\title{
Methodological Approaches to Assessing the Investment Attractiveness of Telemedicine
}

\author{
Olga Blagoveshchenskaya*, Tatiana Ilina, and Anatoly Zemtsov \\ National Research Tomsk State University, 36 Lenin Avenue, 634050, Tomsk, Russia
}

\begin{abstract}
The paper considers modern methodological approaches of Russian and foreign authors to assess the investment attractiveness of the industry. The object of analysis is a new industry - telemedicine. As a result of the study, industry specifics and factors affecting its investment attractiveness were identified. The work also explores methodological approaches to assessing investment attractiveness and investment efficiency. The uniqueness of the study consist in the fact that previously there were no works, approaches and methods analyzing investment attractiveness in terms of their applicability to the selected industry. Based on the results of a critical analysis of the proposed approaches and methods for assessing investment attractiveness, requirements were formed that need to be considered when developing and applying methodological approaches to assessing the investment attractiveness of telemedicine.
\end{abstract}

Keywords: investment attractiveness, telemedicine, telemedicine technologies, e-health.

\section{Introduction}

The term "investment attractiveness" is an ambiguous concept that constantly changes with changes in its characteristics, such as the object and type of investment, the economic situation and the sphere of investment, the nature and characteristics of investment relations of economic entities, etc. Understanding the influence of all these factors allows us to adapt the concept of investment attractiveness to new investment sectors, such as telemedicine.

We will analyze the investment attractiveness of telemedicine, highlighting its distinctive features and summarize the approaches to valuation.

The concept of "investment attractiveness" in theory is considered in two main directions:

1. From the point of view of the object of investment activity, investment attractiveness is understood as the integral characteristic of the industry (enterprise, project, etc.) from the perspective of development prospects, return on investment and the level of investment risks.

2. From the point of view of the subject of investment activity, investment attractiveness is defined as the ability of the investee to satisfy the needs of the investor.

\footnotetext{
* Corresponding author: 89528075555o@gmail.com
} 
Thus, the investment attractiveness is the result of a quantitative or qualitative assessment of the value of the object of investment activity [1].

According to some scholars, there can be no unified definition of this concept, since the goals of assessing investment attractiveness are different for different groups of investors, for example, for banks, investment attractiveness is its solvency, for shareholders - economic efficiency (return on assets) [2].

Given that the features of investing in different industries are associated with differences in the objects of investment and the specificity of factors, we consider the investment attractiveness of telemedicine in this context.

The following types of investments are distinguished according to investment objects and goals: real, venture, financial, social. Venture capital investments are usually associated with the introduction of new technologies and high-tech products with the aim of stimulating the development and scaling of the business, which leads to a significant transformation of the industry. Venture capital investments are most often realized through start-ups; they are highly risky and difficult to forecast investment returns. Real investments are aimed primarily at financing capital investments for the development of an existing business and usually solve current problems. Financial investments are investments in assets and instruments of the financial market in order to preserve savings or increase capital. Social investment is a relatively new type of investment, for which financing of objects and solving social problems are a priority. We will study the essential characteristics of telemedicine to determine the prevailing types of investment, which will become the basis for choosing methodological approaches to analysis and determining the investment attractiveness of this industry.

\section{Materials and methods of research}

Telemedicine technologies are information technologies that provide remote interaction of medical workers among themselves, with patients and (or) their legal representatives [3].

In the world, telemedicine is synonymous with or included in the definition of e-health [4]: "e-health implies the use of Internet technologies by the public, health workers and others to access information, services and support in the field of health and lifestyle; it includes telemedicine, telecommuting, etc."

Thus, telemedicine emerged as a symbiosis of two branches of medicine (healthcare) and the IT industry. The development of telemedicine is due to the introduction of new information technologies, usually through start-ups, which gives reason to consider investing in this industry as a venture. But at the same time, it is social, given that the ultimate goals of the industry remain social, related to medical care.

\section{Results and discussion}

\subsection{Features of telemedicine as an industry}

To research approaches and methods for assessing investment attractiveness for their applicability to telemedicine, it is necessary to determine its features as an industry. Experts highlight the following: development is limited by legislative barriers, does not depend on natural resources, services can only be provided by medical staff, a prerequisite for functioning is the protection of personal data, falsity and often the impossibility of integrating systems between each other.

It is important to note that consultations are carried out exclusively for the purpose of prevention, collection, analysis of complaints and medical history data, assessment of the effectiveness of treatment and diagnostic measures, medical monitoring of the state of health 
and making decisions about the need for the next face-to-face admission (examination, consultation). Their purpose is not the diagnosis and purpose of therapy.

Remote monitoring of the patient should be used only after face-to-face reception by the attending physician (examination, consultation) with the mandatory observance of the requirements of the legislation in the field of personal data and observance of medical secrets through the use of a single identification and authentication system. In rare cases, telemedicine technologies can provide effective treatment or control of its compliance, but this applies only to chronically ill patients[5] who are always under observation. An example of such a technology is Telestore for patients with cardiovascular disease, as the technology helps with a stroke [6].

Today telemedicine technologies are applied to [7]:

- remote diagnosis and counseling of patients, making the so-called "second diagnosis";

- emergency expert assistance by highly qualified doctors in difficult medical cases;

- distance learning of students and medical staff, conducting continuing education courses;

- disaster medicine, for quick access to qualified medical care in hard-to-reach places or places with destroyed infrastructure;

- organization of qualified medical care in hard-to-reach spots, for example, in remote locations, at drilling and shift camps, as well as on sea and river vessels;

- access to the services of centralized and international medical centers and training centers.

Telemedicine technologies are primarily IT and telecommunication technologies[8], therefore, they require a minimum of equipment, but a good Internet network, and can also be implemented very quickly in any medical institution [9].

Thus, telemedicine has four characteristics:

1. Its purpose is to provide clinical support.

2. She overcomes geographical barriers, establishing a connection between users who are physically located far from each other.

3. It includes the use of various types of ICT.

4. Its result is improved public health [10].

\subsection{Existing approaches and methods for assessing the investment attractiveness of telemedicine}

Let us consider the approaches and methods for assessing the investment attractiveness of telemedicine, given its venture and social investment character.

The approach is profitability. Often the probability of success in venture capital investments is described qualitatively: success or failure. For social investments, income is not the main characteristic, as they are focused on social goals. In this case, it is logical to evaluate the effectiveness of the investment attractiveness of telemedicine technologies in two ways.

The first is a cost-benefit analysis. Such work is based on a comparison of patients treated using telemedicine with patients undergoing treatment using traditional methods of providing medical services. In part of the methodologies, only health care costs are taken into account, in the rest, a social approach is used when social costs are considered.

The second is a cost-benefit analysis. This approach is rarely used to evaluate the costeffectiveness of healthcare because of the difficulty in calculating the monetary value of health. For this assessment method, the QALY parameter is used, which shows how much the saved year of quality life will cost for society. For the possibility of making a decision on the economic feasibility of a project, there is a threshold value of QALY, at overcoming of which an event in the field of healthcare is considered economically ineffective. This 
parameter is called "cost-effectiveness threshold" "“willingness to pay threshold", hereinafter referred to as WPT). The WPT indicator is considered to be equal to three GDP per capita [11]:

$\mathrm{WPT}=(3 \times \mathrm{GDP} / \mathrm{N})$,

where WPT is the value of the willingness to pay threshold;

GDP - gross domestic product (for a specific country);

$\mathrm{N}$ - population of the country, number of people.

This method allows you to identify impressive results: QALY $=250.000$ USD (USA) [12] and QALY = 2409 USD (Spain) [13].

Any positive assessment result (increase in utility, benefits or cost reduction) attracts investors and, accordingly, investments. But, unfortunately, these methods sometimes give conflicting results.

Investment attractiveness is often considered in the context of the influence of various factors that are associated with assessing the economic efficiency of investments, as mentioned above, while analyzing profitability, cost, structure and efficiency of capital use, solvency, liquidity, etc.

Approach: risk-return. High risk is associated not only with greater profitability, but also with the ability to make a sharp leap in the development and growth of capital. And this is exactly the approach that is usually considered with venture capital investment. When assessing risks, business activity, property status, financial dependence and others are analyzed. A generalization of the current problems of telemedicine allows us to identify threats and the most likely causes of risks:

- restructuring of staff responsibilities, the need for IT skills training;

- lack of qualified personnel capable of efficiently and quickly interacting with telemedicine systems;

- inaccessibility of modern technologies to the public;

- insufficiently developed regulatory framework and lack of international standards;

- unpreparedness of patients to use a new type of medical care;

- problems of forming a documentary base in the provision of telemedicine services [14];

- the acquisition of equipment takes time and money;

- a change in the health care provider increases the risk of a decline in the quality of care;

- technical problems, which can lead not only to a decline in quality, but also to a denial of service;

- changes in health policies, especially in terms of cost recovery;

- instability of the macroeconomic situation;

- dependence on contractors and the state;

- difficulty in assessing various investments for their intended purpose and determining their total value[15];

- legal protection and licensing of doctors conducting teleconsultations;

- insurance and payment for telemedicine services;

- lack of educational standards and the education itself for telemedicine doctors [10];

- confidentiality problems and others.

Under conditions of uncertainty, the decline in income, competitiveness, changes in market conditions and other factors are also taken into account.

In the provision of medical services, sociality and industry specificity is crucial, since it depends on them whether problems to reduce the incidence rate, injuries, the costs of conducting a medical examination, etc. will be solved. The introduction of telemedicine technologies for large companies is an especially important task, since internal social investments in the development of personnel favorably affect the company's economic performance, and will also affect its investment attractiveness. Experts note that such 
companies have Return on Equity (ROE) at 9.8\%, Return on assets (ROA) at $3.55 \%$, and Return on Sales (ROS) at $2.79 \%$ higher.

Accordingly, the question arises of the nature of the use of economic and non-economic factors in relation to assessing the investment attractiveness of investments in telemedicine. Most methods for assessing the investment attractiveness of the industry use indicators characterizing the growth factors of the industry [16]. As a rule, such indicators depend on the characteristics and specifics of the industry.

Telemedicine growth factors at the present stage are:

- increasing mobility of the population in the country and other countries;

- the complexity, uniqueness and high cost of many new methods of medical analysis;

- the complexity and variety of medical problems leading to the emergence of unique specialists with a narrow profile, unique equipment;

- rapid development of technical capabilities for communication with mobile subscribers anywhere in the world;

- development of mathematical methods of data processing, allowing them to be converted into usable information, as well as distributed databases;

- social networks for doctors and patients;

- creation of medical clusters and incubators;

- competitive selection procedures to finance the most promising developments;

- development of databases, workflow systems and integration of patient data (developed by IBM) [17];

- active development of video conferencing technologies [18].

As noted earlier, it is important to consider the economic and non-economic factors of investment attractiveness. Based on a generalization of the experience of developing telemedicine in different countries, the following factors of its investment attractiveness can be distinguished (Table 1).

Table 1. Telemedicine development factors in different countries.

\begin{tabular}{|c|c|}
\hline Country / Region & Telemedicine Development Factors \\
\hline Europe and USA & Economic factor (high cost of medical services) \\
\hline Portugal [19] & $\begin{array}{c}\text { In some regions, the average age of the population is } \\
\text { higher than in Europe, and the distance to medical } \\
\text { facilities is too large. }\end{array}$ \\
\hline $\begin{array}{c}\text { Scandinavian countries, } \\
\text { Canada }\end{array}$ & $\begin{array}{c}\text { Geographical factor (northern territory, where there are } \\
\text { many hard-to-reach regions where there is a lack of } \\
\text { medical care) }\end{array}$ \\
\hline China & $\begin{array}{c}\text { Geographical and social factors (huge territory and a very } \\
\text { large population) }\end{array}$ \\
\hline Great Britain, Japan & $\begin{array}{c}\text { Social factor (population aging) } \\
\text { African countries }\end{array}$ \\
\hline Cape Verde [20] & $\begin{array}{c}\text { Social factor (population with chronic diseases that } \\
\text { require help and treatment, remote monitoring; lack of } \\
\text { doctors) }\end{array}$ \\
\hline $\begin{array}{c}\text { Solving the problem of providing medical services where } \\
\text { distance is a critical factor (telemedicine as a tool to } \\
\text { expand the access of the population of specialized care to } \\
\text { the country's islands) }\end{array}$ \\
\hline
\end{tabular}

Since innovations in medicine are being introduced sequentially, and usually represent not just one project, but a whole program of innovative transformation of medical services, 
a simple assessment of investment attractiveness will not work because of the complexity and complexity of the investment process. In this case, it is advisable to use scoring assessment methods, which are integrated integrated models that analyze many different factors, and can be used to rank investment objects at investment sites. In addition to quantitative characteristics, qualitative ones can be used here, which makes the entire model abstract. The most optimal method for determining abstract quantities is the expert method, on the basis of which the rating is built. An important element in this is innovative attractiveness and innovative efficiency, since telemedicine is associated with the introduction of innovative technologies. There are four groups of factors of innovative attractiveness: financial (profit, market share, trade volume)[21]; technical; marketing (prestige level, customer satisfaction, etc.) [22] and process (quality, management efficiency, etc.) [23]. There is a steady connection between the number of innovations introduced and the improvement of the financial condition of the company[24]. Sorescu, Chandi, and Prabu analyzed the introduction of radical innovations in pharmacology and noticed that innovation has a greater impact on economic efficiency than improvements in marketing or technology for the production of traditional goods [25].

Therefore, as an economic efficiency, you can use the indicator - the rate of return on investment, which depends on factors of innovative efficiency and which serves as a filter for the selection of investment objects. A survey conducted by Ernst \& Young [15] showed that clinic representatives consider the payback period (for investment projects) and the internal rate of return as important criteria for evaluating the effectiveness of investments in telemedicine, while the values of these indicators vary widely: from 1 year to 10 years payback period and from $20 \%$ to $40 \%$ at the rate of return. The spread of values, according to the respondents, depends on the form of business (premium segment, business segment, etc.), on the geographical factor, on the cost and complexity of equipment and technology, on the completeness of equipment loading, on the qualifications of the staff and the presence of competitors, from profitability and lack of financing and high bank rates..

\section{Conclusion}

Thus, we highlight the main features and requirements that must be taken into account when developing and applying methodological approaches to assessing the investment attractiveness of telemedicine:

- the abstractness of the investment attractiveness of investment objects;

- the relationship of factors of innovative, economic and social (medical) effectiveness;

- limitation of return on investment objects by the minimum rate on return on investment;

- the need to use different approaches to valuation due to the wide industry diversity and the influence of many factors: a market approach to assess external factors, accounting and financial approaches to assess internal factors, a combined approach to assess innovative, economic and social factors, a strategic approach to assess uncertainty, future opportunities and results;

- the priority of an integrated approach that allows you to get an assessment based on industry goals and objectives; external and internal factors; quantitative and qualitative characteristics, investment risks; give an assessment for different types of users, compensating for the shortcomings of complementary methods.

\section{References}


1. O. I. Gavrilyuk, Tools and methods for assessing the investment attractiveness of industrial enterprises: Abstract of dissertation for the degree of candidate of economic sciences (Belgorod: Publishing house BelSTU, 2010)

2. E.A. Melay, A.V. Sergeeva, Approaches to the evaluation of investment attractiveness of the organization: comparative analysis, Bulletin of Tula State University. Economic and legal sciences. 1 (2015)

3. The Federal Law "On the Basics of Protecting the Health of Citizens in the Russian Federation" dated November 21, 2011 N 323-Ф3 (as amended on August 3, 2018), Clause 22, Article 2

4. C. Vandelanotte, A.M. Müller, C.E. Short et al. Present, and Future of eHealth and mHealth Research to Improve Physical Activity and Dietary Behaviors, Journal of nutrition education and behavior 48, 3 (2016)

5. R. Wootton, Twenty years of telemedicine in chronic disease management - an evidence synthesis, Journal of telemedicine and telecare 18, 4 (2012)

6. B.M. Demaerschalk, B.W. Chong et al. American Telemedicine Association: Telestroke Guidelines, Telemedicine and e-health 23, 5 (2017)

7. Niche market review "Diagnostic medicine" (2020, June). http://www.rusventure.ru/ru/programm/analytics/docs/201212_market_med.pdf

8. B. Klaassen, B.J. van Beijnum, H.J. Hermens, Usability in telemedicine systems-A literature survey, International journal of medical informatics 93 (2016)

9. Y. David, X.W. Zhu, L.N. Wang, Store-and-forward telemedicine: Features, advantages, and implementing strategies. IEEE-EMBS Asia pacific conference on biomedical engineering - proceedings, 2 (2002)

10. I.B. Maksimov, A.N. Diashev, et al. Telemedicine: history, analysis of a state and prospects, Journal of Telemedicine and E-Health 3, 8 (2018)

11. R.I. Yagudina, I.V. Sorokovikov, The methodology of conducting the analysis of "cost - utility" in conducting pharmacoeconomic studies. Pharmacoeconomics. Modern pharmacoeconomics and pharmacoepidemiology (2012)

12. S.X. Liu, R. Xiang et al., Economic modeling of heart failure telehealth programs: when do they become cost saving, International Journal of Telemedicine and Applications (2016)

13. N.D. Brunetti, G. Dellegrottaglie et al. Prehospital telemedicine electrocardiogram triage for a regional public emergency medical service: is it worth it? A preliminary cost analysis. Clinical Cardiology 3, 7 (2014)

14. T.M. Isaev, Methods for assessing the economic effectiveness of telemedicine. Issues of Economics and Law, pp. 77-83 (2012)

15. The study of the market of commercial medicine in Russia for 2016 - the first half of 2017: a study by Ernst \& Young LLC.

https://www.ey.com/Publication/vwLUAssets/ey-health-care-report-2017rus/\$FILE/ey-health-care-report-2017-rus.pdf

16. A.B. Teslya, V.K. Kryukova, Justification of the Need for Application of Telemedicine Technologies for Workers of Enterprises Located in Hard-Accessed Regions of the Russian Federation, Scientific bulletin of the Southern Institute of Management, pp. 100-106 (2018)

17. Y. Zhai, J. Gao, B. Chen, et al., Design and Application of a Telemedicine System Jointly Driven by Videoconferencing and Data Exchange: Practical Experience from Henan Province, China, Telemedicine and E-Health 26, 1 (2020) 
18. J.L. Fang, C.A. Collura, R.V. Johnson, et al. Emergency Video Telemedicine Consultation for Newborn Resuscitations: The Mayo Clinic Experience. Mayo Clinic Proceedings 91, 12 (2016)

19. T.C. Oliveira, M.J. Branquinho, et al., State of the Art in Telemedicine-Concepts, Management, Monitoring and Evaluation of the Telemedicine Programme in Alentejo (Portugal). Perspectives on Digital Pathology (2012)

20. A. Correia, V. Azevedo, L.V. Lapão, Implementation of Telemedicine in Cape Verde: Influencing Factors. Acta Medica Portuguesa. 30, 4 (2017)

21. J. J. Hauschildt, S.Salomo. Innovationsmanagement (Munchen: Vahlen, 2011)

22. G. Altmann, Unternehmensführung und Inno- vationserfolg - Eine empirische Untersuchung im Ma- schinenbau (Wiesbaden: Deutscher Universitäts-Verlag, 2003)

23. A. Griffin, PDMA success measurement project: Recommended measures for product develop- ment success and failure. Journal of Product Innovation Management 13, 478-496 (1996)

24. P. Geroski, The profitabilitiy of innovating firms, The Rand Journal of Economics 24, 198-211 (1993)

25. A.B. Sorescu, Sources and financial conse- quences of radical innovation: Insights from pharma-ceuticals, Journal of Marketing 67, 82-102 (2003) 